\title{
CREATINE AND GUANIDOACETIC ACID METABOLISM IN PITUITARY DISEASE
}

\author{
BY \\ J. N. CUMINGS \\ From the Clinical Pathological Laboratory, National Hospital, Queen Square, London
}

(RECEIVED FOR PUBLICATION APRIL 26, 1950)

Schrire (1937) found that patients with an acidophil tumour of the pituitary excreted creatine in the urine, and this was later confirmed (Cumings, 1944). It was also shown in the latter paper that the fasting blood creatine was raised above the normal in acromegaly, and the results of a creatine tolerance test were given in five cases of pituitary disorders. The cause of the creatinaemia and creatinuria in acromegaly is obscure, but it had been shown previously that the urine excretion of creatine paralleled the height of the blood creatine provided that a level higher than $0.6 \mathrm{mg} . / 100 \mathrm{ml}$. had been obtained. Guanidoacetic acid has been shown to be a precursor of creatine (Borsook and Dubnoff, 1940 ; 1941) and its estimation in pituitary disorders does not appear to have been recorded previously. This paper records a large series of patients with pituitary disorders, together with a few cases of thyrotoxicosis, in whom creatine and guanidoacetic acid studies have been made.

\section{Material and Methods}

Creatine studies have been made on 39 subjects consisting of 10 normal controls, 11 with acromegaly, nine with chromophobe adenomata or suprapituitary cysts, six with miscellaneous pituitary disorders, and three with thyrotoxicosis. The diagnosis was made in most cases at operation and by histology, or by clinical and radiological evidence which was unmistakable. Guanidoacetic acid was estimated in the urine in 26 out of the 39 subjects, and, in a few patients, more than one examination was made.

All patients were placed on a meat- and fish-free diet and 24-hourly urines were collected over a five- or six-day period. Creatine and creatinine were estimated according to the principles of the Folin and Wu technique (1919). A creatine tolerance test as described by Tierney and Peters (1943) was performed, usually on the third day, and the blood levels of creatine and creatinine estimated according to the technique of Peters (1942) as in my previous paper, but using a photoelectric colorimeter with a filter of $520 \mu$.

Urinary guanidoacetic acid was estimated as described by Hoberman (1947), following the technique of Dubnoff and Borsook (1941) as modified by Sims (1945), 
after each urine had been treated with arginase to remove any arginine present. The arginase was prepared by the technique described by Hoberman (1947).

\section{Results}

Examples of results in each group are recorded in Appendix 1 and Appendix 2, and one example in each group is shown in the figures.

Normal Controls.--None of the 10 controls showed any creatinuria, and the amount of urinary creatinine was reasonably constant from day to day. The fasting blood creatinine was $0.5 \mathrm{mg}$. $/ 100 \mathrm{ml}$. or below in nine cases and in the other case $0.6 \mathrm{mg}$. $/ 100 \mathrm{ml}$., and this can be regarded as normal since Samuels, Sellers, and McCaulay (1946) obtained figures of up to $0.6 \mathrm{mg} . / 100 \mathrm{ml}$. in normal controls even though Tierney and Peters (1943) found figures of up to $0.5 \mathrm{mg} . / 100 \mathrm{ml}$. only.

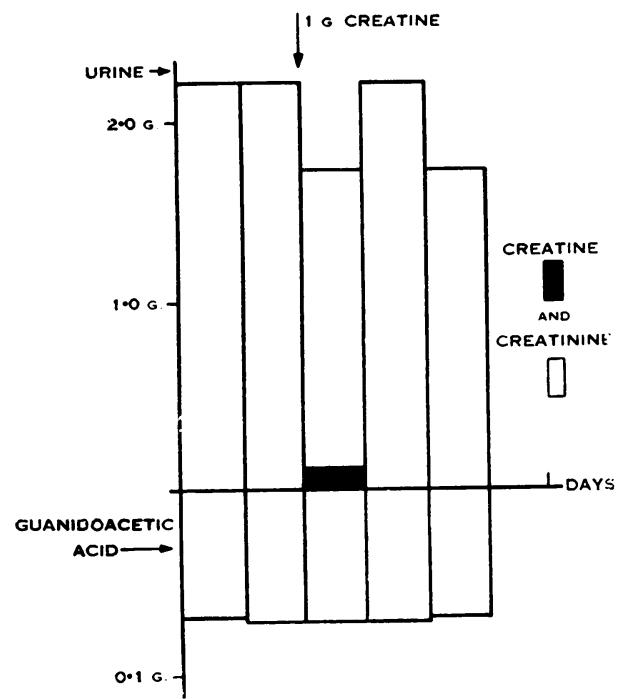

FIG. 1.-Diagram of guanidoacetic acid excretion in a normal control (N. H.).

Chromophobe or Suprapituitary Tumours. - The nine patients in this group showed results identical with the normal control group as regards urinary creatine and creatinine. The fasting blood creatine in all cases was within normal limits, but the rise in blood level was somewhat higher after $1 \mathrm{~g}$. of creatine than was to be seen in the conGuanidoacetic acid was estimated in four of these controls and a normal excretion of $30-50 \mathrm{mg}$. a day was obtained in all except one, a very large muscular man and a heavy manual worker, who excreted $60-80 \mathrm{mg}$. a day. The results found in this patient are shown in Fig. 1. It might be mentioned that not infrequently a little creatine is excreted in the first day of the test as a result of the creatine in the diet of the preceding day.

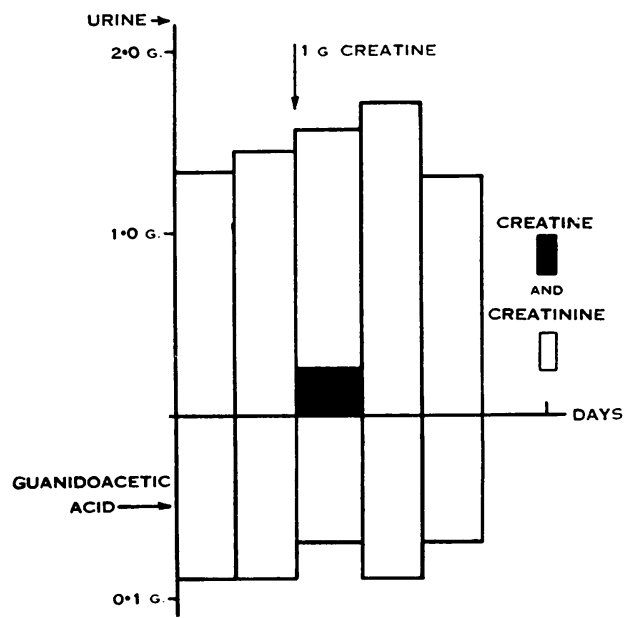

FIG. 2.-Diagram of guanidoacetic acid in a case of chromophobe adenoma. trol group. Guanidoacetic acid was estimated in all except one case, and raised excretion rates were seen in all the patients except one, the only one who had a suprapituitary cyst. The usual excretion was as high as $80-100 \mathrm{mg}$. a day. The 
patient with a raised blood creatinine had a severe nephritis from which he died post-operatively. Fig. 2 shows the findings in one case.

Acromegaly. - There was creatinuria in all except two patients, one of whom was examined nine years after removal of the pituitary acidophil tumour, and the other (S.D.) who was clinically normal following hormonal therapy. There was a raised fasting blood creatine in 10 out of the 11 patients, the only normal level of creatine being seen in the clinically normal patient who had received hormone treatment. The creatine tolerance test gave results similar to those previously recorded (Cumings, 1944).

Guanidoacetic acid was estimated in seven patients in this group, which included the patient apparently cured by hormones and another only examined postoperatively. These two patients showed a slightly raised excretion of guanidoacetic acid of up to about $60-80 \mathrm{mg}$. daily, but one of them excreted very little urine in each 24-hour period. The remaining five typical cases all showed a markedly increased excretory rate, usually of about $100 \mathrm{mg}$. daily.

A few of the patients were examined after operation and after hormone therapy as well as before these treatments. One patient, five years after operation, showed an improvement in the creatinaemia and creatinuria, and, except for one day during the test period, passed no more guanidoacetic acid in the urine than a normal control. Another patient nine years after operation showed no creatinuria even though the fasting blood creatine was slightly raised. One patient who showed the usual chemical findings seen in acromegaly was given hormone therapy, but after six months there were no improvements in blood or urine chemistry though there had been some clinical improvement. The other patient similarly treated, but for a much longer period, was practically normal when examined clinically and pathologically. An example of one of these cases is shown in Fig. 3.

Miscellaneous Pituitary Disorders.This group consisted of two patients with tumours of mixed cell type (both acidophil and chromophobe cells), both of whom were diagnosed in the laboratory as having overactivity of acidophil cells ; three patients with gross obesity and other evidence of pituitary dysfunction; and one very small, thin patient who also had a suprapituitary cyst. All these patients showed creatinuria, together with a raised fasting blood creatine. The very thin patient of the 39 patients examined showed the highest rise in blood creatine after ingestion of $1 \mathrm{~g}$. of creatine by mouth. The guanidoacetic acid excretion of this patient one and a half years after operation was normal even though the

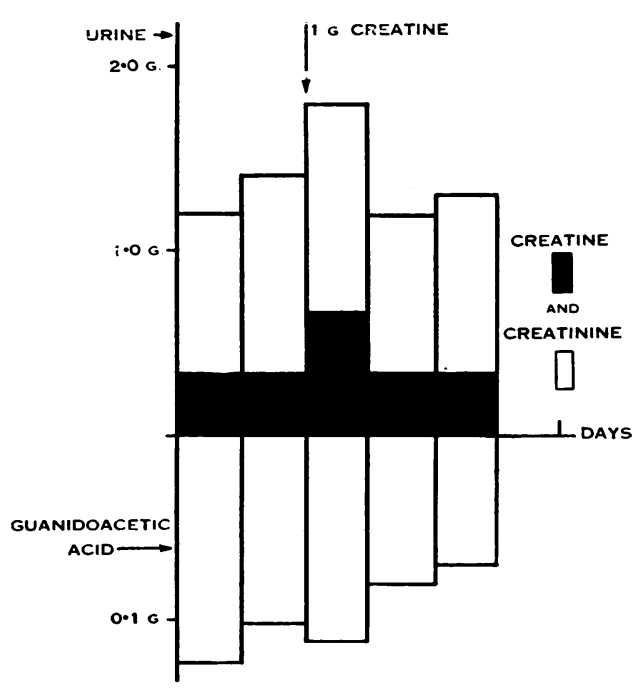

FIG. 3.-Diagram of guanidoacetic acid in a case of acidophil adenoma. 
creatinuria still persisted. Guanidoacetic acid was also estimated in three other patients before operation. The obese patients so examined both showed a raised urinary output. One patient with a so-called "pituitary abscess" gave a

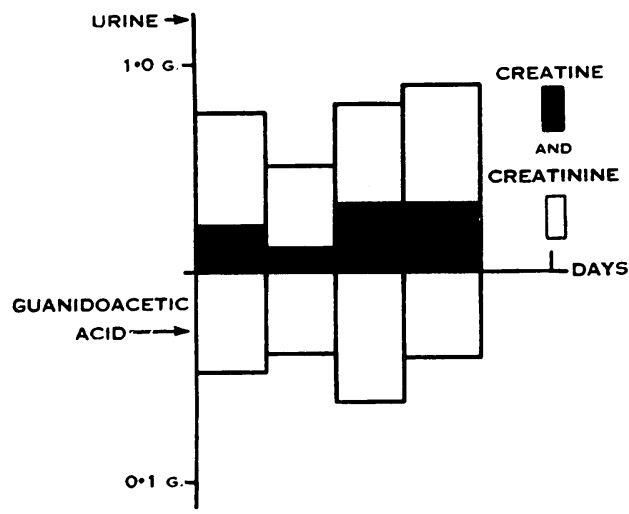

FIG. 4.-Diagram of guanidoacetic acid excretion in a case of thyrotoxicosis. normal rate of excretion of guanidoacetic acid.

Thyrotoxicosis. - Three patients were examined and all showed creatinuria with a fasting blood creatine, although in no case was this latter figure as high as that seen in the cases of acromegaly. All three cases showed a normal excretion of guanidoacetic acid. The results found in a moderately severe case of thyrotoxicosis with a basal metabolic rate of $+75 \%$ are shown in Fig. 4. Table $\mathrm{I}$ is a summary of the blood creatine curves of the cases recorded in Figs. 1-4.

TABLE I

Blood Creatine Curves after 1 g. Creatine in Four Cases Recorded in the Diagrams

\begin{tabular}{|c|c|c|c|}
\hline Condition & Time & $\begin{array}{c}\text { Creatinine } \\
\text { (mg./100 ml.) }\end{array}$ & $\begin{array}{c}\text { Creatine } \\
\text { (mg./100 ml.) }\end{array}$ \\
\hline . $\quad$. & $\begin{array}{l}\text { Fasting } \\
1 \text { hour after creatine } \\
2 \frac{1}{2},, \quad,, \quad,\end{array}$ & $\begin{array}{l}0.9 \\
1.25 \\
1.0\end{array}$ & $\begin{array}{l}0.3 \\
0.55 \\
0.5\end{array}$ \\
\hline Chromophobe adenoma & $\begin{array}{l}\text { Fasting } \\
1 \text { hour after creatine } \\
2 \frac{1}{2},,,, \quad,\end{array}$ & $\begin{array}{l}0.7 \\
0.9 \\
0.8\end{array}$ & $\begin{array}{l}0.5 \\
0.9 \\
0.7\end{array}$ \\
\hline Acromegaly ... & $\begin{array}{l}\text { Fasting } \\
1 \text { hour after creatine } \\
2 \frac{1}{2},, \quad,,,\end{array}$ & $\begin{array}{l}0.62 \\
0.75 \\
0.75\end{array}$ & $\begin{array}{l}0.88 \\
1.75 \\
0.85\end{array}$ \\
\hline Thyrotoxicosis & Fasting & 0.7 & 0.9 \\
\hline
\end{tabular}

\section{Discussion}

The results obtained in the examination of this large series of pituitary disorders confirm the earlier findings in 1944 as far as creatine metabolism is concerned, and there can be no doubt that in acromegaly with an acidophil tumour of the pituitary there is creatinaemia and creatinuria. It is seen that a large part of the ingested creatine is rapidly excreted in the urine and that the blood soon loses its increased quantity of creatine. Previously it had not been possible to distinguish 
biochemically between a normal patient and a patient with a chromophobe adenoma, even though one could distinguish between these two and an acromegalic patient. It was also not possible by creatine metabolic studies to distinguish between thyrotoxicosis and acromegaly. From the results of the guanidoacetic acid studies, however, it is now possible to determine into which of these four groups any one patient falls. Table II shows the distinguishing biochemical features between the normal person and the three other conditions discussed.

TABLE II

Distinguishing Biochemical features of the Normal and Certain Pituitary Disorders

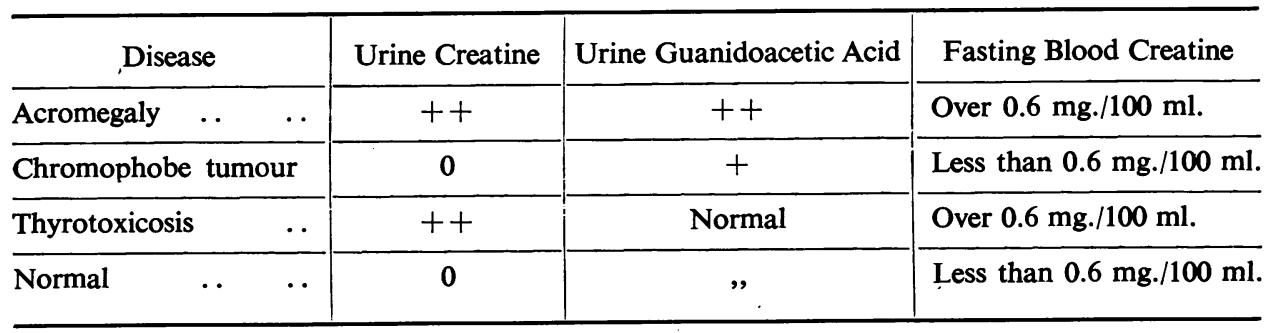

Guanidoacetic acid is formed in the kidneys (Borsook and Dubnoff, 1941 ; Borsook, Dubnoff, Lilly, and Marriott, 1941) by transamidination from the aminoacids glycine and arginine, and is then transformed into creatine by methylation, probably utilizing methionine. This latter process probably takes place in the liver (Borsook and Dubnoff, 1940, 1947; Bloch and Schoenheimer, 1941), although there is some evidence from examinations made in cases of nephritis that this can also take place in the kidneys (Samuels et al., 1946). It would appear, therefore, that the overaction of some of the pituitary cells affects these chains of events and so alters the urinary excretion of these substances.

There is in acromegaly not only an increased production of guanidoacetic acid but also an increased formation of creatine, hence the increase in production of the former substance must be quite considerable. It is different in a patient with a chromophobe adenoma as there is here an excess of guanidoacetic acid but no increase in creatine excretion; it would appear unlikely that any storage of creatine is taking place as this would need to be considerable, and, further, there is no increased excretion of creatinine over the normal, nor is there any creatinaemia. Equally, the excess of guanidoacetic acid must be an excess of production otherwise the blood level of creatine would drop and there would be a lowered excretion of creatinine. Further, because of the normal urinary creatinine and blood creatine it cannot be assumed that the guanidoacetic acid is not being made into creatine. It may be mentioned that in neither acidophil nor chromophobe tumours can any evidence be found biochemically of liver damage, as a number of liver function tests have been carried out in these patients and no abnormality has yet been detected ; further, in one patient only was there any evidence of renal disease, 
and the results obtained in that case, apart from the level of the blood creatinine, were not significantly different from the others in his group.

Borsook and Dubnoff (1947) showed that the presence of creatine in high concentration may retard the methylation of guanidoacetic acid to such an extent as to give a raised excretion of this substance. This cannot be the mechanism in acromegaly, for then one would expect to see the same process in thyrotoxicosis, but in this condition the guanidoacetic acid excretion is normal. It is therefore unlikely that the pituitary thyrotropic hormone plays any part in acromegaly, and further proof of this is seen in the inability of thiouracil to affect the creatinuria in acromegaly as it does in thyrotoxicosis (Schrire, 1948).

Hoberman, Sims, and Engstrom (1948) showed that methyl testosterone given to normal men produced creatinuria and also an increased urinary excretion of guanidoacetic acid, and they state that this is due to an increase in synthesis of creatine as a result of the effect of this hormone on the reactions involved in the synthesis of guanidoacetic acid. Samuels, Henschel, and Keys (1942) showed that if the methyl testosterone be given for some weeks then there is also creatinaemia and creatinuria occurring usually after 10 days' treatment with methyl testosterone. In the same way testosterone propionate as well as methyl testosterone produced similar results although not giving such a high level of excretion of creatine and guanidoacetic acid in the urine (Hoagland, Shank, and Gilder, 1944). These findings would seem to give a hint as to the mechanism causing the disturbance that is found in pituitary disease. It is not suggested that it is necessarily, either of these two hormones that is responsible, but it does seem probable that the acidophil and the chromophobe cells each elaborate hormones that act in the manner suggested by Hoberman et al., and it does seem to be true that the effects of both methyl testosterone and testosterone propionate are those seen in acromegaly. This would seem to be a basis for further study and one on which to build a programme of hormonal therapy for these two types of patients.

\section{Summary}

Creatine studies have been made in 10 normal controls, in 26 patients with pituitary disorders, and in three with thyrotoxicosis, and the urinary excretion of guanidoacetic acid followed in 26 of these 39 subjects. It has been shown to be possible biochemically to distinguish between the normal, the thyrotoxic, the acromegalic, and the patient with a chromophobe adenoma of the pituitary.

The possible causes of the biochemical abnormalities have been discussed and the possibilities of abnormal hormonal activity in the two pituitary disorders mentioned.

I wish to thank the many physicians and surgeons of the National Hospital, and"also Dr. J. S. Richardson, for allowing me to conduct these investigations on their patients and for access to their case records; Drs. J. G. Greenfield and W. Blackwood for their histological opinions; and Mr. R. C. Shortman for his technical help. Lastly I should like to express my appreciation to Dr. E. A. H. Sims, of Yale University School of Medicine, who very kindly sent me a supply of guanidoacetic acid and also informed me of some of his work. 


\section{REFERENCES}

Bloch, K., and Schoenheimer, R. (1941). J. biol. Chem., 138, 167.

Borsook, H., and Dubnoff, J. W. (1940). Ibid., 132, 559.

- (1941). Ibid., 138, 389.

(1947). Ibid., 169, 247.

Lilly, J. C., and Marriott, W. (1941). Ibid., 138, 405.

Cumings, J. N. (1944). Brain, 67, 265.

Dubnoff, J. W., and Borsook, H. (1941). J. biol. Chem., 138, 381.

Folin, O., and Wu, H. (1919). Ibid., 38, 81.

Hoagland, C. L., Shank, R. E., and Gilder, H. (1944). Proc. Soc. exp. Biol., N.Y., 55, 49.

Hoberman, H. D. (1947). J. biol. Chem., 167, 721.

— Sims, E. A. H., and Engstrom, W. W. (1948). Ibid., 173, 111.

Peters, J. H. (1942). Ibid., 146, 179.

Samuels, L. T., Henschel, A. F., and Keys, A. (1942). J. clin. Endocrinol., 2, 649.

- Sellers, D. M., and McCaulay, C. J. (1946). Ibid., 6, 655.

Schrire, I. (1937). Quart. J. Med.n.s., 6, 17.

- (1948). Clin. Sci., 7, 49.

Sims, E. A. H. (1945). J. biol. Chem., 158, 239.

Tierney, N. A., and Peters, J. P. (1943). J. clin. Invest., 22, 595.

\section{A P P E N D I X 1}

In this appendix a representative protocol for one normal control and each type of case discussed is set out.

Normal (E. M.)

\begin{tabular}{|c|c|c|c|c|c|}
\hline \multicolumn{6}{|c|}{ Urine } \\
\hline & Day & Volume & Creatinine & Creatine & Guanidoacetic Acid \\
\hline $\begin{array}{l}1 \\
2 \\
3 * \\
4 \\
5\end{array}$ & $\begin{array}{l}. . \\
\cdots \\
\cdots \\
\cdots \\
.\end{array}$ & $\begin{array}{l}2,300 \mathrm{ml} . \\
1,700 \quad ", \\
1,920 \quad ", \\
1,450 \quad, \\
2,450 \quad,\end{array}$ & $\begin{array}{l}1.20 \mathrm{~g} . \\
1.14, " \\
1.12 ", \\
0.96 ", \\
1.04 ",\end{array}$ & $\begin{array}{l}0 \\
0 \\
0.31 \mathrm{~g} . \\
0 \\
0\end{array}$ & $\begin{array}{l}0.035 \mathrm{~g} . \\
0.052,, \\
0.051 \text {, } \\
0.044 \text { ", } \\
0.056 \text {,", }\end{array}$ \\
\hline
\end{tabular}

Creatine Tolerance Test

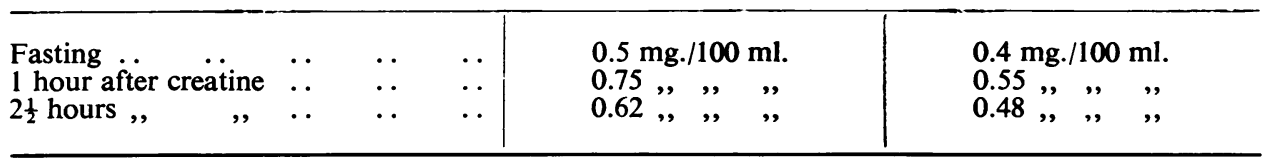

Chromophobe Adenoma.-A single woman of 25 complained of failing vision for seven years, and headache and hirsuties for six years. Menstruation was normal. Examination showed a coarse skin, which was greasy, and there was a definite deposit of hair over the face. There was a bitemporal lower quadrant defect with rather pale 
neurological disorder. There was evidence of vasomotor instability. The pulse rate was between 80 and 90 ; the B.M.R. was slightly raised $(+20 \%)$. Clinically she was considered to have a mild thyrotoxicosis, and under treatment she improved in hospital and after discharge.

\begin{tabular}{|c|c|c|c|c|c|c|}
\hline \multicolumn{7}{|c|}{ Urine } \\
\hline & Day & & Volume & Creatinine & Creatine & Guanidoacetic Acid \\
\hline $\begin{array}{l}1 \\
2 \\
3 * \\
4 \\
5\end{array}$ & $\begin{array}{l}. . \\
\cdots \\
\cdots \\
.\end{array}$ & $\begin{array}{l}. \\
\ddot{ } \\
\ddot{.} \\
.\end{array}$ & $\begin{array}{l}1,900 \mathrm{ml} . \\
2,250 \quad, \\
2,530 \quad ", \\
1,190 \quad ", \\
1,700 \quad ",\end{array}$ & $\begin{array}{l}1.42 \mathrm{~g} . \\
1.47, \\
1.73, " \\
0.95, " \\
1.32, "\end{array}$ & $\begin{array}{l}0.48 \mathrm{~g} . \\
0.40 \mathrm{~g} \\
0.21, " \\
0.42, " \\
0.23, "\end{array}$ & $\begin{array}{l}0.047 \mathrm{~g} . \\
0.041 \text { ", } \\
0.055 \text { ", } \\
0.061, " \\
0.065 \text {," }\end{array}$ \\
\hline
\end{tabular}

Creatine Tolerance Test

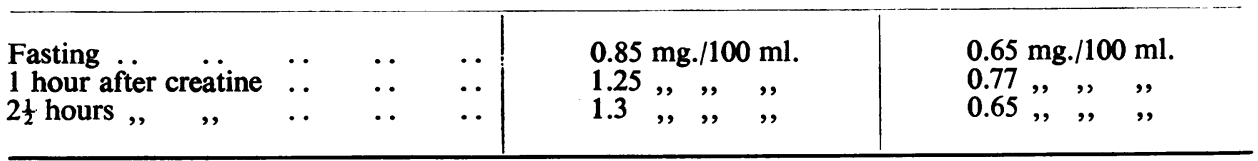

* Creatine tolerance test (1 g. by mouth) on this day.

\section{A P P E N D I X 2}

This appendix contains a brief clinical abstract of the cases recorded in Figs. 2, 3, and 4.

Fig. 2 (13106/49. N.H.).-A woman of 32 with a history of amenorrhoea and headaches for 17 years, and poor vision for nine months.

Examination showed a well-built, normal-looking woman. There was primary optic atrophy and a complete temporal field loss on the right side only. There was also an early loss in the upper and outer part of the left field. The uterus and ovaries were small, but there were no other abnormal physical signs. A radiograph of the skull showed considerable enlargement of the pituitary fossa. Operation revealed a typical chromophobe adenoma (verified histologically). The tumour was removed and there was uneventful recovery.

Fig. 3 (7371/48. N.H.).-A woman of 42 whose sole complaint was of failing vision for $3 \frac{1}{2}$ months.

Examination showed a middle-aged, alert woman with unmistakable acromegalic features. There was a large head, massive maxillae, and slightly prognathous jaw. There was little soft tissue hypertrophy. Hands and feet were all large and broad. The skin was smooth and of a fine texture. In the eyes both fundi showed definite pallor of the discs, and some bitemporal scotomata were present. The blood pressure was raised, but no other abnormal physical signs were found. Radiologically the pituitary fossa was enlarged.

At operation a pituitary acidophil adenoma (confirmed histologically) was found and partially removed. 
Fig. $4(31707 / 49$. W.H.).-A woman of 50 with a six months' history of tremor. There was said to be no loss in weight.

Examination revealed a middle-aged, rather thin woman with bilateral exophthalmos, with tremor of the outstretched hands, but no obvious sweating. The thyroid showed a diffuse soft enlargement. The pulse rate varied from 90 to 100 a minute, but the blood pressure was normal. B.M.R. $+75 \%$; blood count normal ; blood cholesterol $197 \mathrm{mg}$. per $100 \mathrm{ml}$. Thiouracil produced considerable improvement in the clinical condition apart from the exophthalmos. There has been a gain in weight of $4 \mathrm{lb}$. to 8 st. $10 \frac{1}{2} \mathrm{lb}$. 